\title{
PEMASARAN ONLINE UNTUK USAHA MIKRO KECIL MENENGAH SOSIS BAKAR BU WIWIK
}

\author{
Alfiana $^{1^{*}}$, Shintya Budiyanti², Rofifah Qonita Hamzah ${ }^{3}$, Dita Alia Farah ${ }^{4}$, Yovita Kiik ${ }^{5}$ \\ 1,2,3,4,5 Fakultas Ekonomi dan Bisnis, Universitas Widyagama Malang \\ *Email Korespondensi: alfiana@widyagama.ac.id
}

Submitted : 13 September 2021; Revision : 16 September 2021; Accepted : 2 Oktober 2021

\begin{abstract}
ABSTRAK
Sejak pandemi COVID-19, beberapa lini bisnis tidak dapat beroperasi secara maksimal, sehingga beberapa pengusaha mulai mencari alternative untuk menjual produk mereka secara omline. Usaha Mikro, Kecil dan Menengah atau (UMKM) merupakan salah satu kategori bisnis yang mendapatkan dampak paling besar. Bisnis Online merupakan salah satu hal yang diminati di bidang ekonomi yang dilakukan untuk memperluas market share. Maka program Kuliah Pengabdian Masyarakat (KPM) yang dilakukan oleh Universitas Widyagama, Malang berusaha membantu salah satu UMKM di Kabupaten Malang yaitu Sosis Bakar Bu Wiwik dengan membuatkan pengurusan media sosial dengan merencanakan konten, foto-foto produk, desain feeds Instagram, menulis caption, dan mengunggah konten. Semuanya dilakukan pada media sosial instagram Sosis Bakar Bu Wiwik.
\end{abstract}

Kata kunci : Pemasaran, UMKM, Sosis Bakar

\begin{abstract}
Since the COVID-19 pandemic, several business lines have not been able to operate optimally, so some entrepreneurs have started looking for alternatives to sell their products online. Micro, Small and Medium Enterprises or (MSMEs) are one of the business categories that get the most impact. Online business is one of the things that are in demand in the economic field which is done to expand market share. So the Community Service Lecture (KPM) program conducted by Widyagama University, Malang is trying to help one of the MSMEs in Malang Regency, namely Sosis Bakar Bu Wiwik by developing social media management by planning content, product photos, designing Instagram feeds, writing captions, and uploading content. Everything was done on the social media of Bu Wiwik's Baked Sausage Instagram.
\end{abstract}

Keywords : Marketing, MSMEs, Grilled Sausage

\section{PENDAHULUAN}

Pandemi COVID-19 telah memberikan dampak luar biasa pada perekonomian nasional, khususnya di sektor Usaha Mikro, Kecil, dan Menengah (UMKM). Berdasarkan hasil survei Asian Development Bank (ADB) terdapat 48,6\% UMKM Indonesia yang tutup sementara pada tahun 2020 karena pandemi COVID-19. Adapun UMKM yang bertahan mengalami penurunan permintaan $30 \%$. Permasalahan utama yang harus dihadapi para pelaku UMKM pada saat pandemi adalah turunnya penjualan, karena demand yang merosot dan terhambatnya distribusi ketika pergerakan orang dan barang yang terbatas. Oleh sebab itu pemerintah aktif mendorong para pelaku UMKM di Indonesia melebarkan penetrasi pasar ke ranah digital. Kementerian Koordinator Bidang Perekonomian mencatat, pada periode 14 Mei hingga 9 Juni 2020, sekitar 301.115 UMKM telah beralih pada platform digital. (Airlangga Hartanto, 2019). Selain itu dengan pengembangan digitalisasi UMKM akan membuat ekonomi digital di Indonesia pada 2025 akan menjadi terbesar di Asia Tenggara. Meski begitu ada tiga kendala yang dihadapi oleh UMKM yaitu; pertama, pelaku UMKM masih terkendala pada kapasitas produksi barang. Bahkan banyak UMKM yang gagal dipasar digital, karena tidak memenuhi permintaan pasar digital. Kedua, 
kualitas daya tahan pelaku UMKM yang belum merata. Dikarenakan di pasar digital ini para pelaku harus dapat bersaing dengan perusahaan besar yang selama pandemi juga beralih menggunakan platform digital. Ketiga, diperlukan penguatan edukasi literasi digital dan penguatan sumber daya manusia para pelaku usaha UMKM (Wardhana, 2015; Farell, Thamrin and Novid, 2019; Saputeri and Abidin, 2019; Anggoro and Hasugian, 2020; Kumala and Junaidi, 2020; Sumarni and Melinda, 2020; Susanti, 2020; Susanti, Istiyanto and Jalari, 2020; Wibowo and Santoso, 2020; Machfudz, 2021). Sebab selama ini literasi digital dan kualitas sumber daya manusia para pelaku UMKM sangat minim, sehingga berdampak pada kurang maksimalnya dalam memproduksi produk unggulan masingmasing. Padahal, mayorutas pelaku usaha UMKM ingin mempraktikan bisnis digital dalam pengembangan usahanya (Susanti, Istiyanto and Jalari, 2020).

Bisnis digital merupakan salah satu bidang dalam ekonomi yang diminati pada saat ini. Banyak perusahaan yang sedang melakukan transisi atau bahkan sudah beralih dari bisnis konvensional menjadi bisnis digital. Hal ini dilakukan untuk memperluas market share perusahaan dalam bisnis mereka. Ditambah dengan adanya pandemi COVID-19 pada saat ini yang mengakibatkan beberapa pengusaha mulai mencari jalan untuk menjual produk mereka dikarenakan beberapa lini bisnis tidak dapat beroperasi secara maksimal jika secara offline. Dari beberapa kategori bisnis di Indonesia, Usaha Mikro, Kecil dan Menengah atau (UMKM) merupakan salah satu kategori bisnis yang mendapatkan dampak dari pandemi COVID-19, dikarenakan keuangan dari pelaku bisnis kategori UMKM beberapa bahkan belum stabil sebelum adanya pandemi COVID-19 dan makin diperparah dengan adanya pandemi tersebut (Anggoro and Hasugian, 2020; Kumala and Junaidi, 2020; Machfudz, 2021).

Bisnis digital sendiri memiliki beberapa kekuatan dan kelemahan yang harus dicermati sebelum memulainya. Terdapat kekuatan bisnis digital untuk UMKM yaitu; Modal yang dikeluarkan relatif kecil dikarenakan tidak membutuhkan penyewaan tempat usaha; Jangkauan yang luas untuk semua kalangan dimanapun mereka berada; dan juga dapat dikerjakan kapan saja dan dimana saja. Kekurangannya sendiri yaitu adalah koneksi internet yang belum didapatkan oleh semua orang di Indonesia. Maka dari itu, pengusaha mulai mencoba merambah ke dunia bisnis digital untuk memperluas jaringan bisnisnya. Namun dengan adanya operasi bisnis digital sendiri akan mengakibatkan beberapa hambatan lainnya. Pada kasus ini, hambatan tersebut yaitu ketidakpahaman sebagian pelaku bisnis terhadap perkembangan bisnis digital mulai dari pembuatan bisnis digital dan pengoperasian bisnis digital.

Para pelaku UKM seharusnya juga sudah mulai memanfaatkan media digital sebagai salah satu upaya pemasaran produknya sehingga konsumen lebih mengenal produk yang dihasilkan oleh UKM tersebut. Salah satu platform media digital yang bisa digunakan oleh para UKM dalam meningkatkan pemasaran produknya adalah Instagram.Instagram sendiri merupakan aplikasi yang berbasis media seperti foto dan video yang disertai dengan deskripsi. Selain itu, Instagram juga menyediakan akun bisnis yang dapat menunjang kebutuhan pelaku UMKM. Salah satu UMKM yang kami tempati untuk KPM yaitu Sosis Bakar Bu wiwik adalah UMKM yang berdiri sejak 2018 awal dengan berjualan utama yaitu sosis bakar dan ada banyak jualan lainnya seperti es jeruk, dan jasuke. Pada awal pandemi usaha ini sangat berdampak sekali karena pemilik usaha berjualan keliling mencari keramaian sedangkan pandemi ini menghambat penjualan. Oleh karena itu kami mahasiswa Universitas Widyagama Malang kelompok 11 Kuliah pengabdian Masyarakat (KPM) berinisiatif membuat social media yaitu instagram untuk melakukan pemasaran pada produk utama yaitu Sosis Bakar. Tujuan dari KPM ini dilakukan adalah untuk membantu UMKM khususnya Sosis Bakar Bu Wiwik melalui sosial media planning serta pembuatan media platform marketplace (Instagram) untuk meningkatkan penjualan dari bisnis UMKM tersebut. Pembuatan media platform ini ditujukan untuk menambahkan cara berbisnis yang lebih bersaing, kompeten dan memperluas jaringan bisnis dari pelaku UMKM (Wardhana, 2015; Kumala and Junaidi, 2020; Susanti, Istiyanto and Jalari, 2020). 
Manfaat dari artikel ini adalah sebagai referensi untuk UMKM agar mengetahui alur pembuatan konten media sosial Selain itu sebagai referensi untuk UMKM untuk mengetahui lebih banyak tentang bisnis digital.

\section{METODE}

Pada masa pandemi ini kami melakukan eksekusi kegiatan secara offline dan online. Kerja online kami lakukan dari rumah masing masing. Media komunikasi yang digunakan melalui aplikasi google meet, Zoom, whatsapp.

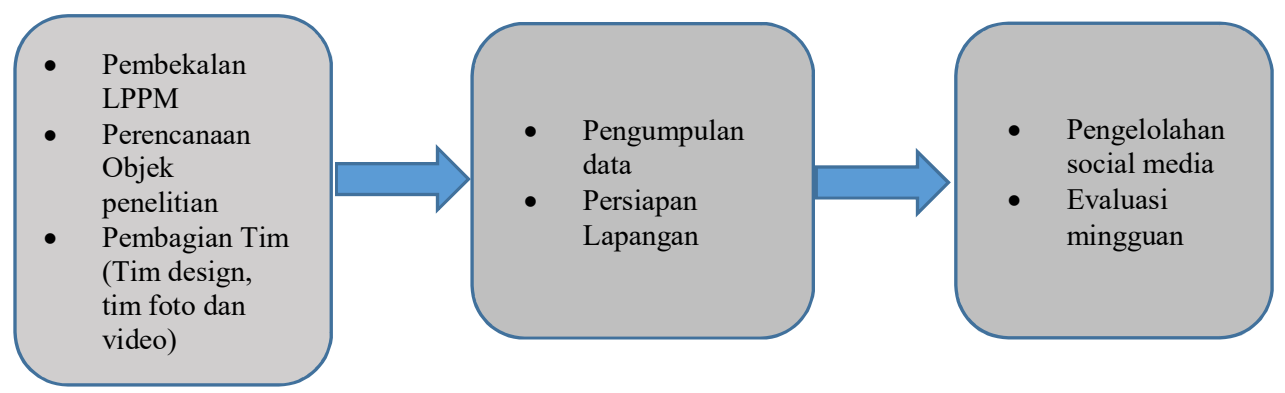

Gambar 1. Metode Pelaksanaan KPM

\section{a. Tahap Persiapan}

Pada tahap ini, diberikannya pembekalan oleh LPPM mengenai pelaksanaan kegiatan KPM, pemilihan UMKM yang menjadi objek, pemilihan ketua kelompok dan koordinasi antara mahasiswa dan Pembina untuk merancang kegiatan apa yang akan dilakukan saat tahap pelaksanaan. Kemudian mahasiswa melakukan diskusi secara mandiri untuk pembagian tugas masing-masing anggota secara adil dan disepakati oleh bersama. Setelah itu kami menyampaikan rancangan kegiatan yang akan kami lakukan pada Pembina dan Pemilik UMKM Sosis Bakar Bu Wiwik yang menggambarkan penjelasan mengenai kegiatan yang akan kami lakukan. Selain itu mahasiswa juga mulai membuat rancangan untuk sosial media dari UMKM tersebut.

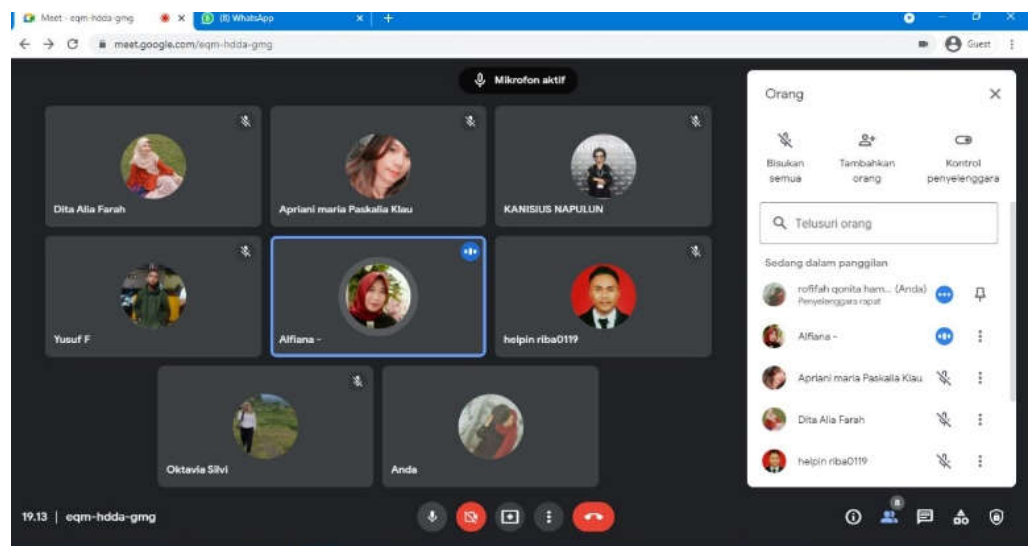

Gambar 2. Tahap Koordinasi dengan Pembina melalui Googlemeet

\section{b. Tahap Pelaksanaan}

Terdiri atas pengumpulan data, penyiapan lapangan, pelaksanaan kegiatan pengabdian kepada masyarakat, dan tindak lanjut. Pengampu kegiatan KPM dan 
mahasiswa peserta KPM berdiskusi serta memilih UMKM apa yang akan dijadikan sebagai media pelaksanaan KPM Setelah UMKM terpilih, mahasiswa berdiskusi bersama pemilik UMKM mengenai latar belakang, ide, dan konsep dari UMKM. Pada tahap ini kami melakukan kegiatan pengumpulan data dari pemilik usaha, merancang konsep dan mulai mengerjakan tugas masing-masing yang sudah ditentukan sebelumnya. Dimana masingmasing bagian, koordinator yang bekerja mengoordinir seluruh kegiatan untuk sosial media. Tim Design yang membuat design untuk konten postingan di Instagram, tim foto produk yang membuat foto dan video produk, serta membuat caption pada instagram. Pelaksanaan kegiatan KPM dilakukan secara daring, dan apabila diperlukan maka berdiskusi tatap muka diperbolehkan dengan tetap mengikuti protokol kesehatan.

\section{c. Tahap Tindak Lanjut}

Yang dilakukan adalah berkoordinasi antara semua tim untuk memulai mengelola Instagram dari UMKM "Sosis Bakara Bu Wiwik" tersebut dengan mempublikasikan seluruh hasil kami baik foto, design dan caption yang telah disiapkan. Koordinasi dan konsultasi tim dilakukan kembali setelah semua data terkumpul. Data yang telah didapat lalu di-input dan diolah. Mahasiswa KPM juga memberikan follow up kegiatan yang telah dilakukan kepada pemilik UMKM tiap minggunya, serta meminta evaluasi dari pemilik UMKM terhadap apa yang telah dikerjakan oleh mahasiswa KPM agar hasil yang didapat memuaskan serta sesuai yang diharapkan oleh pemilik UMKM.

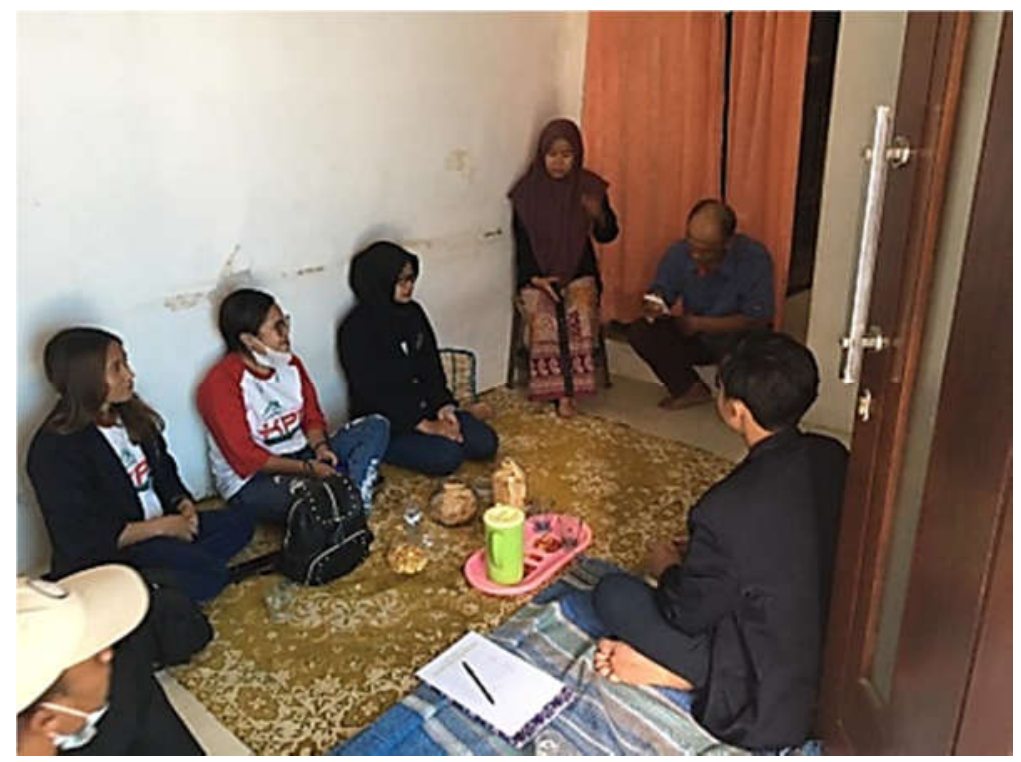

Gambar 3. Koordinasi dengan Pemilik UMKM

\section{HASIL DAN PEMBAHASAN}

Sosial Media ini dibuat dengan tujuan untuk memasarkan sosis bakar lebih luas lagi. Program kegiatan ini diawali dengann tahap perencanaan awal, serta pengonsepan tentang apa saja yang akan dilakukan untuk menumbuhkan konten bagi media sosial Instagram "Sosis Bakar Bu Wiwik" yang. Setelah itu dilakukan proses desain grafis, dan juga foto produk sebagai aspek aspek yang perlu dipenuhi untuk menciptakan suatu konten yang menarik.Setelah semua aspek selesai, seluruh aspek tersebut digabungkan menjadi beberapa post Instagram yang akhirnya akan dipost di Instagram "Sosis Bakar Bu Wiwik". Hasil yang diperoleh dari kegiatan KKN ini adalah terisinya konten di feeds Instagram "Sosis Bakar Bu Wiwik". "Sosis Bakar Bu Wiwik" ini sendiri adalah UMKM yang berdiri 
pada tahun 2018 yang menjual produk utama yaitu sosis bakar. Kegiatan yang kami lakukan untuk digital marketing "Sosis Bakar BuWiwik" adalah membantu dalam pemasaran produk "Sosis Bakar Bu Wiwik" lebih luas lagi dan banyak konsumen berminat.

Selama satu bulan, kelompok KPM 11 dengan topik "Marketing Online untuk UMKM" telah bekerja sama membantu UMKM terkait, yaitu "Sosis Bakar Bu Wiwik", dalam memasarkan produknya dan memperkenalkan merek dagangnya pada masyarakat yang cakupannya lebih luas melalui pemasaran digital. Dalam prosesnya, setiap individu dalam kelompok memiliki tugasnya masing-masing. Tugas-tugas tersebut terbagi ke dalam tim desainer grafis, fotografer. Capation yang sudah terpenuhi yaitu terisinya konten di Instagram "Sosis Bakar Bu Wiwik" dengan desain grafis yang segar dan tone of voice yang sesuai dengan target pasar, yaitu usia anak-anak sampai dengan orang dewasa. Tim fotografer dan desain grafis juga membantu untuk membuat tampilan produk yang menarik bakal calon konsumen dengan foto-foto yang terlihat profesional dan grafis dengan perpaduan warna yang pas. Peningkatan yang diperoleh sejauh ini adalah naiknya kunjungan ke profil Instagram "Sosis Bakar Bu Wiwik".
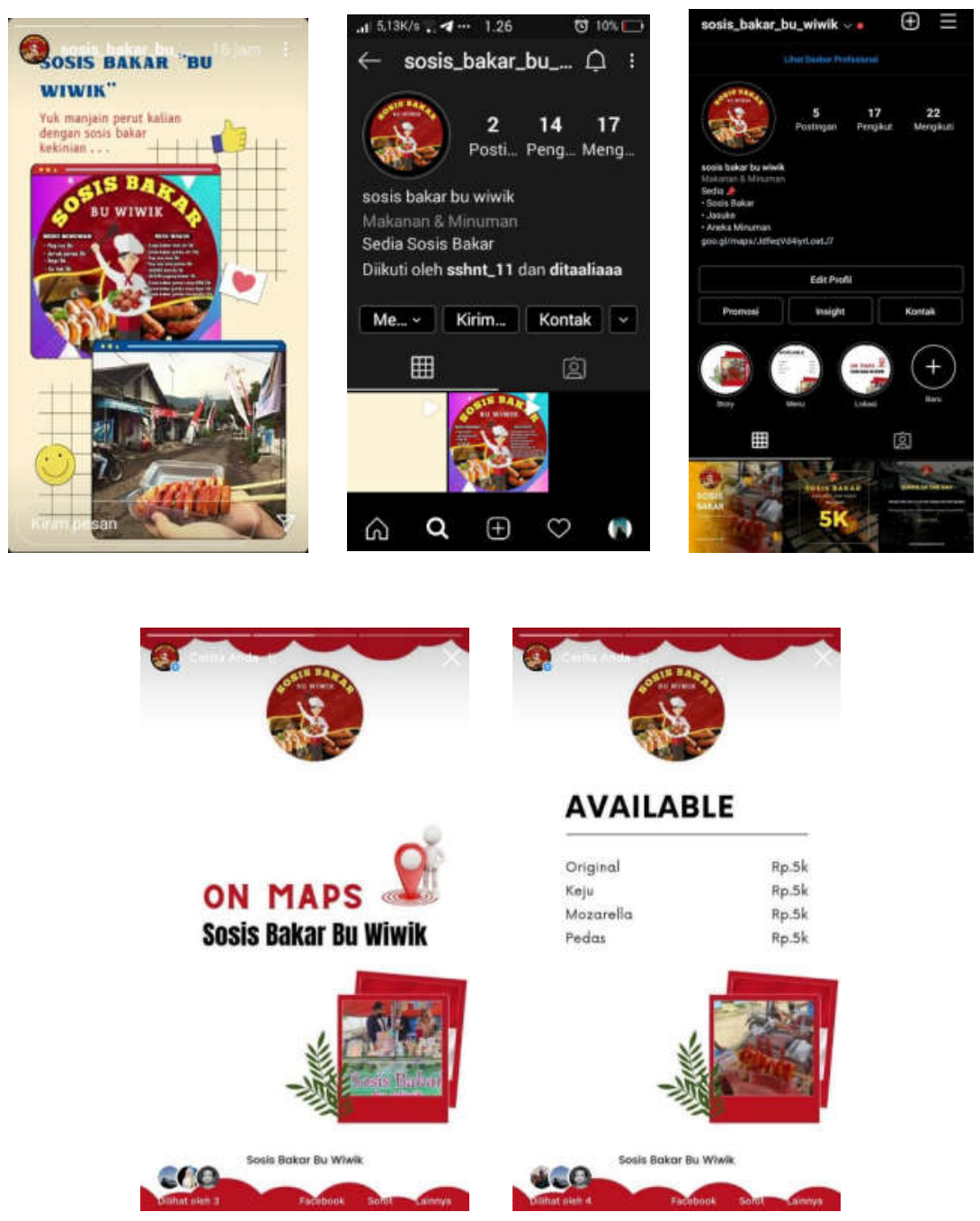

Gambar 4. Hasil dari Pembuatan Instagram 


\section{DAMPAK DAN MANFAAT}

Sosial media merupakan salah satu media yang mempermudah komunikasi interaktif antara pengusaha dengan siapapun, termasuk konsumen, dan berbagai pihak yang berkepentingan, kapanpun dan berada dimanapun. Sosial media sangat membantu sebagai penghubung informasi dan komunikasi dari produsen ke konsumen di manapun mereka berada dan berapapun jaraknya.Manfaat yang paling penting dari media sosial ini adalah tidak berbayar dan tidak memerlukan software khusus.

Manfaat dari penerapan sosial media pada UMKM ini adalah Sebagai sarana iklan/promosi yang tercepat, praktis dan gratis serta meningkatnya penjualan karena masyarakat jadi tau ada produk sosis bakar di daerah rumah mereka. Selain itu UMKM dapat mengetahui kompetitor dan bisa mempelajari apa yang harus dilakukan selanjutnya dan jadi lebih update karena mempelajari produk lain melalui media sosial. Rekomendasi dalam artikel ini adalah UMKM harus mendapatkan bantuan dalam memfokuskan pada revolusi industri komunikasi sehingga penjualan online bisa menjangkau konsumen lebih luas dan banyak, terlebih lagi dengan adanya pandemi COVID-19 yang berlangsung membuat pengguna internet menjadi naik dari sebelumnya, sehingga dalam momen ini setelah kami membantu "Sosis Bakar Bu Wiwik" dalam digital marketing-nya alangkah lebih baik jika "Sosis Bakar Bu Wiwik" terus melakukan digital marketing agar usahanya bisa berkembang dan memiliki penjualan yang baik.

\section{KESIMPULAN}

UMKM merupakan sektor yang vital bagi perekonomian Indonesia karena menyerap banyak tenaga kerja, oleh karena itu perekonomian Indonesia sangat dipengaruhi oleh UMKM. Saat ini industri sedang mengalami perubahan ke arah digital karena adanya revolusi teknologi informasi yang mengakibatkan pemasaran dari sebuah usaha berubah yang pada mulanya masih berbentuk tradisional dan konvensional menjadi digital, pemasaran secara digital atau yang biasa disebut digital marketing bisa dimanfaatkan oleh pelaku UMKM agar bisa mendapatkan konsumen yang lebih luas lagi dan memperbanyak penjualan produk mereka. Dengan begitu pada kegiatan KPM ini mendorong UMKM agar bisa tetap beraktifitas secara digital dengan membantu digital marketing untuk UMKM "Sosis Bakar Bu Wiwik".

\section{UCAPAN TERIMA KASIH}

Ucapan terimakasih disampaikan kepada Rektor Universitas Widyagama Malang yang telah memberikan kesempatan untuk ikut dalam progran KPM. Dan kepada Ketua LPPM yang telah memberikan arahan terhadap keberhasilan KPM, dan mitra Sosis Bakar $\mathrm{Bu}$ Wiwik, serta semua semua anggota kelompok 11, KPM 2021-2 Universitas Widyagama, Malang.

\section{REFERENSI}

Airlangga Hartanto, 2019 'Selama Pandemi COVID-19, Sebanyak 301.115 UMKM beralih ke digital' https://www.antaranews.com/berita/1563584/selama-pandemi covid-19-sebanyak-301115-umkm-beralih-ke-digital.

Anggoro, D. and Hasugian, H. (2020) 'Implementasi Digital Marketing Pada UKM Guna Meningkatkan Pemasaran dan Penjualan Produk Di Masa Pandemi Covid-19', JURPIKAT (Jurnal Pengabdian Kepada Masyarakat), 1(3), pp. 384-391. 
Farell, G., Thamrin, T. and Novid, I. (2019) 'Pelatihan Pemanfaatan Digital Marketing Dalam Pengembangan Pemasaran Dan Kewirausahaan UKM pada Kota Sawahlunto', Suluah Bendang: Jurnal Ilmiah Pengabdian Kepada Masyarakat, 19(1), pp. 42-47.

Kumala, R. and Junaidi, A. (2020) 'Strategi Bisnis Dan Pemanfaatan Kebijakan Pajak Di Masa Pandemi COVID-19 Dan Era New Normal (Studi Kasus Pelaku UKM Marketplace)', in. Prosiding Seminar STIAMI, pp. 98-103.

Machfudz, M. (2021) 'Kontinyuitas Pendampingan Pelaku Ekonomi Kreatif Berbasis Singkong Selama Terjadi Wabah Covid-19 Guna Menjaga Eksistensi dan Keberlangsungan Usahanya Melalui Stimulan Dana Usaha', Jurnal Aplikasi Dan Inovasi Ipteks "SOLIDITAS" (J-SOLID), 4(1), pp. 61-68.

Saputeri, A. and Abidin, M.Z. (2019) 'Pengaruh Kualitas Produk, Kualitas Layanan Dan Lokasi Terhadap Kepuasan Konsumen Sosis Bakar King's Kota Banjarbaru' .

Sumarni, T. and Melinda, L.D. (2020) 'Media Sosial dan E-commerce sebagai Solusi Tantangan Pemasaran Pada Masa Pandemi Covid-19 (Studi Kasus: UMKM Warung Salapan)', ATRABIS: Jurnal Administrasi Bisnis (e-Journal), 6(2), pp. 163-171.

Susanti, A., Istiyanto, B. and Jalari, M. (2020) 'Strategi UKM pada Masa Pandemi Covid19’, KANGMAS: Karya Ilmiah Pengabdian Masyarakat, 1(2), pp. 67-74.

Susanti, E. (2020) 'Pelatihan Digital Marketing Dalam Upaya Pengembangan Usaha Berbasis Teknologi Pada Umkm di Desa Sayang Kecamatan Jatinangor', Sawala: Jurnal pengabdian Masyarakat Pembangunan Sosial, Desa dan Masyarakat, 1(2), pp. 36-50.

Wardhana, A. (2015) 'Strategi Digital Marketing dan Implikasinya Pada Keunggulan Bersaing UKM Di Indonesia', in. Seminar Nasional Keuangan Dan Bisnis IV, pp. 327-337.

Wibowo, J. and Santoso, R. (2020) 'Pembuatan Digital Marketing dan Marketing Channel untuk UKM PJ Collection', JPM17: Jurnal Pengabdian Masyarakat, 5(01), pp. 8291. 